\title{
viruses
}

ISSN 1999-4915

www.mdpi.com/journal/viruses

Article

\section{Anti-CMV-IgG Positivity of Donors Is Beneficial for alloHSCT Recipients with Respect to the Better Short-Term Immunological Recovery and High Level of CD4+CD25high Lymphocytes}

\author{
Emilia Jaskula ${ }^{1,2, \dagger}$, Dorota Dlubek ${ }^{1,2, \dagger}$, Agnieszka Tarnowska ${ }^{2}$, Janusz Lange ${ }^{2}$, \\ Monika Mordak-Domagala ${ }^{2}$, Krzysztof Suchnicki ${ }^{2}$, Mariola Sedzimirska ${ }^{2}$, Agata Borowik ${ }^{2}$, \\ Sylwia Mizia ${ }^{2}$ and Andrzej Lange ${ }^{1,2, \dagger, *}$
}

1 L. Hirszfeld Institute of Immunology and Experimental Therapy, Polish Academy of Sciences, Wroclaw 53-114, Poland; E-Mails: emiljask@wp.pl (E.J.); ddlubek@wp.pl (D.D.)

2 Lower Silesian Center for Cellular Transplantation with National Bone Marrow Donor Registry, Wroclaw 53-439, Poland, E-Mails: agnieszka.tarnowska@poczta.fm (A.T.); jahlange@wp.pl (J.L.); mmordak@o2.pl (M.M.-D.); suchnicki@dctk.wroc.pl (K.S.); sedzimirska@dctk.wroc.pl (M.S.); borowik@dctk.wroc.pl (A.B.); sylwia.mizia@gmail.com (S.M.)

$\dagger$ These authors contributed equally to this work.

* Author to whom correspondence should be addressed; E-Mail: lange@iitd.pan.wroc.pl; Tel.: +48-71-370-9961; Fax: +48-71-337-1382.

Academic Editor: Eric O. Freed

Received: 2 December 2014 / Accepted: 16 March 2015 / Published: 23 March 2015

Abstract: Hematopoietic stem cell transplantation from anti-cytomegalovirus immunoglobulin $\mathrm{G}$ (anti-CMV-IgG) positive donors facilitated immunological recovery post-transplant, which may indicate that chronic CMV infection has an effect on the immune system. This can be seen in the recipients after reconstitution with donor lymphocytes. We evaluated the composition of lymphocytes at hematologic recovery in 99 patients with hematologic malignancies post hematopoietic stem cell transplantation (HSCT). Anti-CMV-IgG seropositivity of the donor was associated with higher proportions of CD4+ $\left(227.963 \pm 304.858 \times 10^{6} v s .102 .050 \pm 17.247 \times 10^{6}\right.$ cells $\left./ \mathrm{L}, p=0.009\right)$ and CD4+CD25high $\left(3.456 \pm 0.436 \times 10^{6}\right.$ vs. $1.589 \pm 0.218 \times 10^{6}$ cells $\left./ \mathrm{L}, p=0.003\right)$ lymphocytes in the blood at hematologic recovery. The latter parameter exerted a diverse influence on the risk of acute graft-versus-host disease (GvHD) if low $\left(1.483 \pm 0.360 \times 10^{6} v s .3 .778 \pm 0.484 \times 10^{6}\right.$ cells $/ \mathrm{L}$, 
$p<0.001)$ and de novo chronic GvHD (cGvHD) if high $\left(3.778 \pm 0.780 \times 10^{6} v\right.$ s. $2.042 \pm 0.261 \times 10^{6}$ cells $/ \mathrm{L}, p=0.041$ ). Higher values of CD4+ lymphocytes in patients who received transplants from anti-CMV-IgG-positive donors translated into a reduced demand for IgG support (23/63 vs. 19/33, $p=0.048)$, and these patients also exhibited reduced susceptibility to cytomegalovirus (CMV), Epstein-Barr virus (EBV) and/or human herpes 6 virus (HHV6) infection/reactivation $(12 / 50$ vs. 21/47, $p=0.032)$. Finally, high levels $(\geq 0.4 \%)$ of $\mathrm{CD} 4+\mathrm{CD} 25$ high lymphocytes were significantly associated with better post-transplant survival $(56 \%$ vs. $38 \%$, four-year survival, $p=0.040)$. Donors who experience CMV infection/reactivation provide the recipients with lymphocytes, which readily reinforce the recovery of the transplanted patients' immune system.

Keywords: anti-CMV serostatus; HSCT; lymphocyte reconstitution; CD4+CD25high lymphocytes; GvHD; herpes virus infection

\section{Introduction}

Alloreactivity and poor immune system recovery leading to life-threatening complications post-hematopoietic stem cell transplantation (HSCT) remains a significant challenge for researchers. At present, we believe that the recognition of foreign human leukocyte antigens (HLAs) evokes a vigorous response involving cytokine production, known as a cytokine storm [1-4]. Although the advanced stage of acute graft-versus-host disease (aGvHD) is associated with a level of HLA disparity, a sizeable proportion of patients may still survive despite relatively poor matching $[5,6]$. Under these conditions, it is believed that $\mathrm{T}$ regulatory cells (Tregs) present in the blood can control the vigorousness of the alloreactive response [7-9]. Twenty years ago, the phenotype of this cell population was described as CD4+CD25high by Sakaguchi et al. [10]. This population meets the criteria for cells that control the immune response using suppressor cell machinery, which functions in cells with interleukin 2 (IL-2) containing environments [11-13]. In particular, IL-2-activated CD4+CD25high lymphocytes (forkhead box P3 (FoxP3)+) may exert both specific and nonspecific suppression of the immune response as bystander cells [14-17]. aGvHD is recognized as a failure of these IL-2-activated CD4+CD25high lymphocytes $[18,19]$. Notably, seropositivity of donors plays a positive role making recipients less susceptible to aGvHD [20-24]. It is also known that cytomegalovirus (CMV) infection sustained in affected individuals life-long influences the immune system changing the profile of T cells in blood [25]. The fate of HSCT largely depends on the lymphocyte composition of the transplant material [26,27], which is different in patients having and lacking chronic CMV infection [28]. However, the issue on the effect of the donors anti-cytomegalovirus immunoglobulin $\mathrm{G}$ (anti-CMV-IgG) seropositivity on aGvHD and survival is controversial. This might be due to the presence of several confounding factors that may bias the final results, including site specific classification of transplant related morbidities in multicenter studies [29,30]. The conclusion of the study by Ljungman et al. [31-33] suggest that the beneficial effect of anti-CMV-IgG positivity is mediated by donors T cells. Therefore, we focused on the effect of donors IgG CMV seropositivity on the immune system recovery in patients post HSCT. 
The novel aspect of our paper is that donor anti-CMV-IgG positivity was associated with a higher proportion of CD4+CD25high lymphocytes, which likely causes the recipient to be less susceptible to aGvHD. In addition, recipients of anti-CMV-IgG negative donors were doing poorly post HSCT in terms of the overall number of CD4+ cells, and they demanded more frequent intravenous IgG support. Finally, patients who presented with a CD4+CD25high lymphocyte proportion $\geq 0.4 \%$ enjoyed better survival than those with the proportions below $0.4 \%$.

\section{Materials and Methods}

\subsection{Patient Characteristics}

In total, 99 patients underwent transplantation at our institution from 2007-2013, and these patients were followed post-HSCT. They received either marrow (BM-4 patients) or peripheral blood progenitor cells (PBPC-94 patients, one patient received PBPC + BM) from matched sibling (SIB: 40 patients) or unrelated donors (MUD: 59 patients).

All donors were clinically screened according to the WMDA guidelines what including in addition to the routine viral make up and also serological profile of antibodies against herpes viruses (CMV, Epstein-Barr virus (EBV), (herpes simplex virus HSV). A total number of anti-CMV-IgG positive donors equaled 64 individuals. Positive and negative anti-CMV-IgG donors differed with respect to the age (mean \pm SEM: $39.2 \pm 1.5$ vs. $32.5 \pm 2.2$ years old, $p=0.014$, respectively).

In total, 67 and 32 patients followed myeloablative (MAC) and reduced (RIC) conditioning regimens, respectively. All MUD patients except one also received anti-lymphocyte antibodies: 51 patients received anti-thymocyte antibodies (ATG; Fresenius, Munich, Germany), and 7 patients received alemtuzumab (Campath; Genzyme, Cambridge, MA, USA). Within the SIB group, as part of their conditioning regimen, 13 patients received ATG, and 3 patients received Campath. The patient characteristics are presented in Table 1. All patients received cyclosporine A at a dose adjusted to a trough value of $200 \mathrm{ng} / \mathrm{mL}$. The dose was tapered after three months, and it was usually discontinued by 6 months post-HSCT. Patients with a serum IgG level below $500 \mathrm{mg} \%$ received routine intravenous immunoglobulin support (KIOVIG; Baxter, Lessines, Belgium).

The patients were discharged from the hospital between 30 and 60 days post-transplant and were followed on an outpatient basis. The patients were invited to appear at two-week intervals or at any time when symptoms suggesting the presence of post-transplant complications were noticed. Blood work included peripheral blood lymphocyte profiling and microbial/viral surveillance.

The starting point of our lymphocyte study was the first day of hematologic recovery (granulocytes $>500 / \mu \mathrm{L}$; from +6 to +39 days post-HSCT, median: 14 days). At the time of hematologic recovery, $92 \%$ patients had chimerism in the blood that exceeded $90 \%$.

aGvHD and cGvHD were diagnosed according to the European Society for Blood and Marrow Transplantation and the National Institutes of Health guidelines, respectively.

Epstein-Barr virus (EBV), CMV, and human herpes virus 6 (HHV6) DNA copies were detected in the blood (from hematologic reconstitution performed 3 times at one-week intervals during the first month post-HSCT and then at one-month intervals until 100 days post-HSCT, followed by 4 times per 
year during routine check-ups). Viral DNA copy numbers were always assessed when post-HSCT complications were found.

Table 1. Patient and donor characteristics.

\begin{tabular}{ll}
\hline Patients & \\
\hline Number $(n)$ & 99 \\
Age (median, range) & $45,6-65$ \\
Gender (female/male) & $54 / 45$ \\
Type of transplantation (alternative/SIB) & $59 / 40$ \\
Transplant material (PBPCs/BM) & $94 / 41$ PBPCs + BM \\
\hline Diagnosis & \\
\hline AML & 53 \\
ALL & 23 \\
Other lymphoproliferative disorders & 3 \\
Myeloproliferative disorders & 9 \\
Myelodysplastic syndrome & 11 \\
Conditioning regimen: & \\
Myeloablative & 67 \\
Reduced intensity & 32 \\
\hline aGvHD grade & \\
\hline I & 55 \\
$I$ & 14 \\
$I I$ & 13 \\
$I I I$ & 5 \\
$I V$ & 12 \\
\hline CMV IgG serostatus & \\
\hline anti-CMV-IgG negative & 20 \\
anti-CMV-IgG positive & 78 \\
Data not available & 1 \\
\hline Donors & $31,19-62$ \\
\hline Age (median, range) & $31,48 / 51$ \\
SIB donors (median, range) & \\
MUD donors (median, range) & \\
Gender (female/male) & \\
\hline CMV IgG serostatus & \\
\hline anti-CMV-IgG negative & \\
anti-CMV-IgG positive & \\
Data not available & \\
\hline
\end{tabular}

All patients with herpes virus reactivation except one had $>100$ DNA copies of CMV, HHV6, and/or EBV per $10^{5}$ cells in the blood from 1-33 weeks (median: 6 weeks) after CD4+CD25high lymphocyte assessment. Herpes virus infection/reactivation events, including CMV, EBV, and/or HHV6 infection/reactivation, during the first year post-transplant were observed in 48/99 patients. 
All donors and recipients gave written consent to the use of their blood work results in scientific elaborations presented on a group basis in an anonymous fashion. The whole project was granted approval by the local Bioethics Committee (KB-52/2010).

The whole group of patients and its subgroups - anti-CMV-IgG donors positive and negative graft recipients, and those with in vivo T cells depletion-were tested separately.

\subsection{Phenotypic Analysis}

Whole blood was used for membrane staining and one-step density gradient centrifugation (Lymphoprep: $d=1.077 \mathrm{~g} / \mathrm{mL}$; Nycomed Pharma AS, Oslo, Norway) was used for intracellular FoxP3 labeling in isolated mononuclear cell fractions. Flow cytometry was performed using a FACSCalibur flow cytometer (Becton Dickinson, San Jose, CA, USA) with CellQuest Pro software (Becton Dickinson) to acquire cells. The following monoclonal antibodies (Mo-Abs) were used for cell surface and intracellular staining after permeabilization: PerCP-anti-CD4, FITC-conjugated anti-CD25, APC-anti-CD45, and PE-conjugated anti-FOXP3 (eBioscience, San Diego, CA, USA).

Phenotypic analyses were performed using WinMDI software. Generally, 20,000 cells were acquired. Lymphocytes were analyzed in the gated population, which lacked cells with granulocyte or monocyte characteristics (CD45high, SSC low). In 16 patients, the proportion of CD4+CD25high lymphocytes correlated with the proportion of FoxP3 + CD4+ lymphocytes $(R=0.551, p=0.028)$.

\subsection{EBV, $C M V$, and HHV6 Quantification}

The numbers of CMV, EBV, and HHV6 DNA copies in peripheral blood cells were determined using real-time polymerase chain reaction (PCR) and a LightCycler II (Roche, Mannheim, Germany). The sequences of the PCR primers and the probe were selected from the BALF5 region of EBV, the US17 region of CMV, and the U67 region of HHV6. PCR was performed as previously described [34].

\subsection{Anti-CMV IgG Antibody Quantification}

Anti-CMV IgG antibodies were detected in sera with the use of CMV IgG ELISA Test System (Zeus Scientific, Inc. Branchburg, NJ, USA). Briefly, recipient' and donor' sera and control samples were incubated in microtitere plate wells pre-coated with inactivated CMV antigen. Specific anti-CMV-IgG antibodies if attached to the coated wells were identified with peroxidase-labeled anti-Human IgG antibodies and the reaction was visualized adding 3',5,5'-tetramethylbenzidine (TMB)-peroxidase substrate. The staining intensity generated after hydrolysis of the peroxidase substrate was read in the spectrometer. The results were interpreted according to the manufacturer's instructions $[22,35]$.

\subsection{CRP Quantification}

C-reactive protein (CRP) was measured routinely in blood at least twice weekly employing specific antibodies (CardioPhase hsCRP — Simens, Marburg, Germany) and nephelometer readings (BN ProSpec System-Simens, Marburg, Germany). 


\subsection{Statistical Analysis}

Statistical analysis was performed using CSS Statistica for Windows (version 10) software (Stat-Soft Inc., Tulsa, OK, USA, 2010). The Mann-Whitney U-test and the Kruskal-Wallis test were used for nonparametric, unpaired samples, and the Kaplan-Meier and log-rank tests were used for overall survival analysis and logistic regression in a multivariate analysis to assess the differences between the investigated groups. Additionally, correlations were calculated using Spearman's rank correlation test. Differences between samples were considered significant at $p<0.05$.

\section{Results}

Donor anti-CMV-IgG negativity resulted in (I) lower numbers of CD4+ lymphocytes in the blood at hematologic recovery $\left(102.050 \pm 17.247\right.$ vs. $227.963 \pm 304.858 \times 10^{6}$ cells $\left./ \mathrm{L}, p=0.009\right)$; (II) a greater proportion of patients that were on intravenous IgG support during the first 100 days post-HSCT (19/33 vs. 23/63, $p=0.048)$; and (III) a higher risk of herpes virus reactivation $(21 / 47$ vs. 12/50, $p=0.032)$ and that of aGvHD (20/33 vs. 23/64, $p=0.020)$.

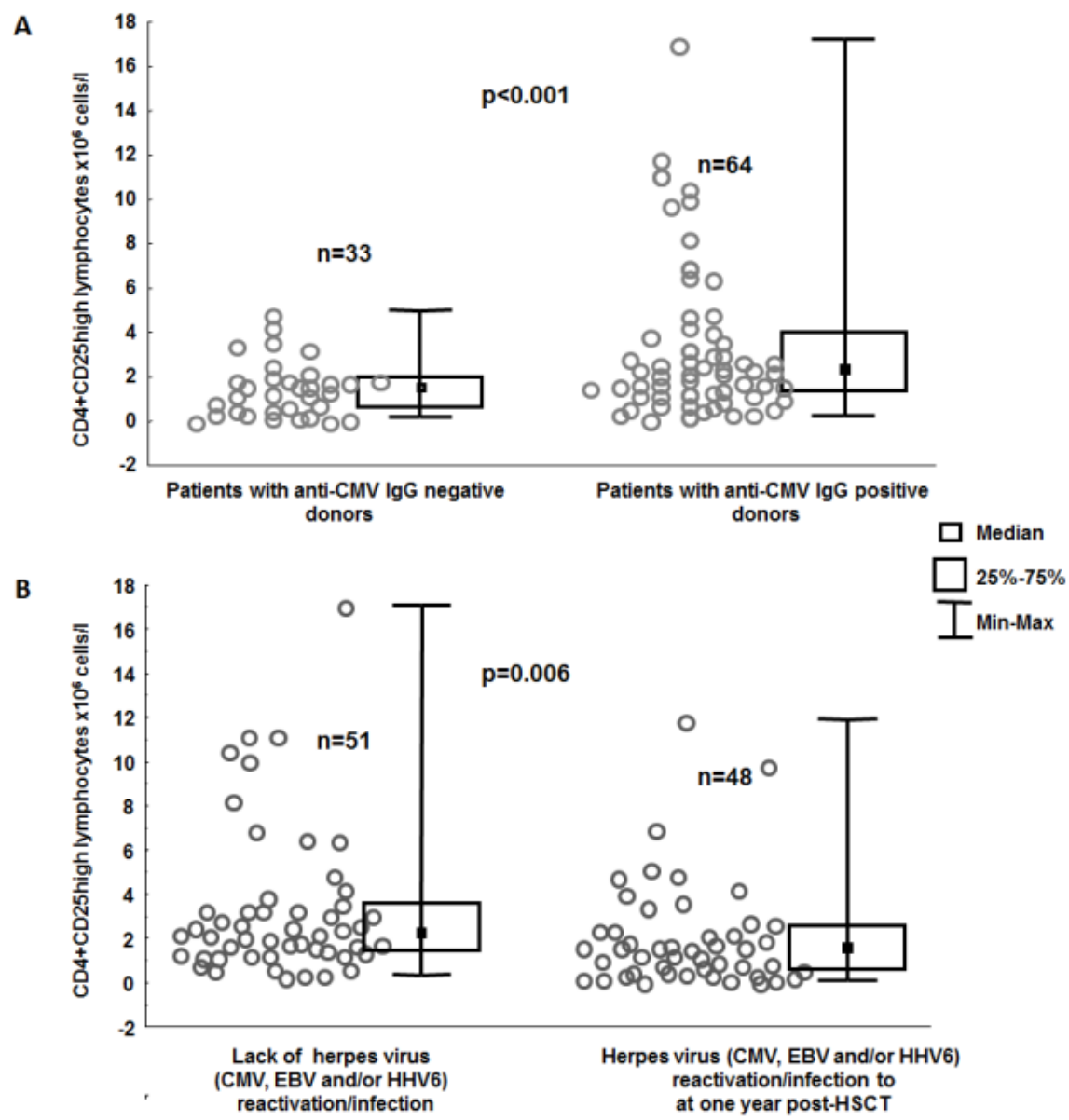

Figure 1. Numbers of CD4+CD25high lymphocytes in the blood determined at the beginning of hematologic recovery in groups of patients stratified according (a) to their anti-CMV IgG donor serostatus (b) and with or without herpes virus (cytomegalovirus (CMV), Epstein-Barr virus (EBV) and/or human herpes 6 virus (HHV6)) reactivation/infection at one year post-HSCT. 
Blood work revealed that the above group of patients receiving a graft from anti-CMV-IgG negative donors had lower proportions and numbers of CD4+CD25high lymphocytes $(0.374 \% \pm 0.030 \%$ vs. $0.503 \% \pm 0.041 \%, p=0.036 ; 1.589 \pm 0.218 \times 10^{6} v s .3 .456 \pm 0.436 \times 10^{6}$ cells $/ \mathrm{L}, p=0.003$, Figure $\left.1 \mathrm{~A}\right)$ as compared to their counterparts grafted from $\mathrm{CMV} \mathrm{IgG} \mathrm{positive} \mathrm{donors.}$

Proportions and counts of CD8+ and CD16+CD56+ lymphocytes in the blood at hematologic recovery were investigated against donor anti-CMV-IgG CMV serostatus. It was found that the proportions $(29.512 \% \pm 1.741 \%$ vs. $22.514 \% \pm 2.019 \% p=0.041)$ and at the trend level the numbers of CD8+ lymphocytes $\left(240.867 \pm 34.251 \times 10^{6}\right.$ cells $/ \mathrm{L} v s .96 .850 \pm 13.001 \times 10^{6}$ cells $\left./ \mathrm{L} p=0.062\right)$ were higher in patients receiving grafts from anti-CMV-IgG seropositive donors as compared to those grafted from anti-CMV-IgG negative donors, but not when CD16+CD56+ lymphocytes were considered.

Interestingly, an increased risk of herpes virus reactivation (CMV, EBV, and/or HHV6) was associated with reduced levels of CD4+CD25high lymphocytes in the blood $\left(2.180 \pm 0.349 \times 10^{6}\right.$ cells/L vs. $3.482 \pm 0.477 \times 10^{6}$ cells $/ \mathrm{L}, p=0.006 ; 0.370 \% \pm 0.030 \%$ vs. $0.539 \% \pm 0.045 \%, p<0.001$; Figure $1 \mathrm{~B}$ ). This association between herpes viruses (CMV, EBV, and/or HHV6 reactivation) and reduced levels of CD4+CD25high lymphocytes was found in the whole-group analysis and in the subgroup of patients who received ATG or Campath $(0.320 \% \pm 0.029 \%$ vs. $0.548 \% \pm 0.072 \%, p<0.001 ; 1.445 \pm 0.217 \times$ $10^{6}$ cells/L vs. $2.322 \pm 0.326 \times 10^{6}$ cells $\left./ \mathrm{L}, p=0.011\right)$.

When patients receiving grafts from anti-CMV-IgG positive and negative donors were analyzed separately, it appeared that the observation drawn from the whole group analysis was valid for the subgroup composed of patients grafted from anti-CMV-IgG positive donors $\left(2.639 \pm 0.582 \times 10^{6}\right.$ cells $/ \mathrm{L}$ vs. $4.015 \pm 0.606 \times 10^{6}$ cells $/ \mathrm{L}, p=0.027 ; 0.414 \% \pm 0.050 \%$ vs. $\left.0.563 \% \pm 0.059 \%, p=0.053\right)$, but in the anti-CMV-IgG negative donors subgroup reduced proportions $(0.320 \% \pm 0.03 \%$ vs. $0.470 \% \pm 0.050 \%$ $p=0.022$ but not counts of CD4+CD25high $\left(1.467 \pm 0.266 \times 10^{6}\right.$ cells $/ \mathrm{L} v s .1 .803 \% \pm 0.380 \times 10^{6}$ cells $/ \mathrm{L}$, $p=0.385)$ were associated with the risk of herpes virus reactivation.

Multivariate analysis demonstrated that, in terms of the risk of herpes virus (CMV, EBV, and/or HHV6) reactivation (Table 2$)$, the percentage of CD4+CD25high lymphocytes ( $\mathrm{OR}=0.089, p=0.022$ ), but not that of CD4+ lymphocytes (which failed to reach a significant position in the preliminary steps of the forward step-wise regression analysis), was a significant and independent factor along with CMV serostatus $(\mathrm{OR}=4.737, p=0.010)$ and the level of donor-recipient matching $(\mathrm{OR}=3.150, p=0.051)$. In the subgroup of patients who received ATG or Campath, low percentages of CD4+CD25high lymphocytes $(\mathrm{OR}=0.062, p=0.033)$ and the $\mathrm{CMV}$ donor/recipient serostatus $\left(\mathrm{R}+/ \mathrm{D}^{-}\right)(\mathrm{OR}=5.784$, $p=0.010$ ) were found to have significant effects (Table 2).

Table 2. Multivariate analysis of factors associated with herpes virus (CMV, EBV, and/or HHV6) infection/reactivation.

\begin{tabular}{lccc}
\hline Parameters & Percentage of CD4+CD25high lymphocytes & HLA mismatch & Anti-CMV IgG serostatus (D-/R+) \\
\hline Entire group, $\boldsymbol{n}=\mathbf{9 9}$ & & & \\
\hline Coefficient & -2.421 & 1.147 & 1.555 \\
$\boldsymbol{p}$ value & 0.022 & 0.051 & 0.010 \\
Odds ratio & 0.089 & 3.150 & 4.737 \\
$\mathbf{- 9 5 \%} \mathbf{C l}$ & -4.489 & -0.004 & 0.389 \\
$\mathbf{+ 9 5 \%} \mathbf{C l}$ & -0.353 & 2.298 & 2.722 \\
\hline
\end{tabular}


Table 2. Cont.

\begin{tabular}{cccc}
\hline In vivo T cell-depleted group (patients receiving ATG or Campath), $\boldsymbol{n}=\mathbf{7 3}$ & \\
\hline Coefficient & -2.779 & 1.196 & 1.755 \\
$\boldsymbol{p}$ value & 0.033 & 0.061 & 0.010 \\
Odds ratio & 0.062 & 3.306 & 5.784 \\
$\mathbf{- 9 5 \%} \mathbf{C l}$ & 0.005 & 0.945 & 1.537 \\
$\mathbf{+ 9 5 \%} \mathbf{C l}$ & 0.794 & 11.570 & 21.764 \\
\hline
\end{tabular}

* Table 2 shows the results of the forward stepwise logistic regression analysis. During the first step analysis, we included factors that had already been suggested [23,34,36-39] to contribute to the risk of herpes virus reactivation, including the type of donor (sibling or unrelated), the level of donor-recipient HLA matching (9/10 or less vs. 10/10 and sibling-matched transplantations), anti-CMV IgG serology (donor serology and donor/recipient serology: negative/positive), mode of transplantation (MAC vs. RIC), transplant material (peripheral blood progenitor cells (PBPCs) vs. bone marrow (BM)), and the percentages and numbers of CD4+ and CD4+CD25high lymphocytes.

aGvHD was observed in 44 patients, and 14, 13, 5, and 12 of these patients suffered from grades I, II, III, and IV, respectively. A total of 24 of these patients progressed to cGvHD, and cGvHD was diagnosed de novo in 21 patients. A total of 18 patients died within 100 days of HSCT, and these individuals were excluded from the analysis of cGvHD risk factors.

To analyze in some depth the association between GvHD and proportions/numbers of CD4+CD25high cells in the blood the entire group of patients was subdivided into three subgroups according to the manifestation of aGvHD: (I) absent; (II) appearing at hematologic recovery; or (III) appearing at a later time point post-transplant. The numbers of CD4+CD25high lymphocytes in the blood at hematologic recovery were higher in patients who did not develop aGvHD during the post-transplantation period than in patients who did develop aGvHD during that time $\left(3.778 \pm 0.484 \times 10^{6}\right.$ cells/L vs. $1.483 \pm 0.360 \times 10^{6}$ cells $/ \mathrm{L}, p<0.001$ ), as well as those who developed aGvHD at a later time (10 days to 11 weeks, median: 3 weeks, $3.778 \pm 0.484 \times 10^{6}$ cells $/ \mathrm{L} v s .1 .921 \pm 0.285 \times 10^{6}$ cells $/ \mathrm{L}, p=0.045$, Figure 2). Very similar associations were seen in the patients grafted from anti-CMV-IgG positive donors $\left(4.257 \pm 0.615 \times 10^{6}\right.$ cells $/ \mathrm{L}$ vs. $2.027 \pm 0.375 \times 10^{6}$ cells $/ \mathrm{L}, p=0.012 ; 0.546 \% \pm 0.365 \%$ vs. $0.425 \% \pm 0.092 \% p=0.004$; ) but not from CMV IgG negative donors $\left(2.152 \pm 0.432 \times 10^{6}\right.$ cells/L vs. $1.233 \pm 0.194 \times 10^{6}$ cells $/ \mathrm{L} p=0.111 ; 0.317 \% \pm 0.036 \%$ vs. $\left.0.412 \% \pm 0.043 \%, p=0.298\right)$.

To validate the hypothesis regarding the effect of toxicity and major infectious complications prior to hematological recovery on the numbers of CD4+CD25high lymphocytes, we examined the toxicity grades and C-reactive protein (CRP) levels in the patient group. Higher CRP values three to five days prior to hematologic recovery were somewhat associated with higher proportions of CD4+ lymphocytes $(R=0.267, p=0.008)$ but not with CD4+CD25high lymphocytes $(R=0.018, p=0.858)$ in the blood. No significant associations between toxicity grades or the proportions or numbers of either CD4+ or CD4+CD25high lymphocytes were observed.

Additionally, the effect of the use of anti-lymphocyte serum (74\% of patients received ATG or Campath) on the association between aGvHD and low numbers of CD4+CD25high lymphocytes was excluded because patients in the in vivo T cell-depleted group had lower numbers of CD4+CD25high lymphocytes if they suffered from aGvHD $\left(2.052 \pm 0.250 \times 10^{6}\right.$ cells $/ \mathrm{L} v s .5 .092 \pm 0.776 \times 10^{6}$ cells $\left./ \mathrm{L}, p<0.001\right)$; this finding was also observed in the entire group analysis. A similar finding was also observed in the 
multivariate analysis, indicating that low numbers of CD4+CD25high lymphocytes $(\mathrm{OR}=0.589$, $p=0.031)$ and an unrelated transplantation $(\mathrm{OR}=2.619, p=0.047)$ setting were independent and significant risk factors of aGvHD in patients who received and lacked in vivo T cell depletion (Table 3 ).

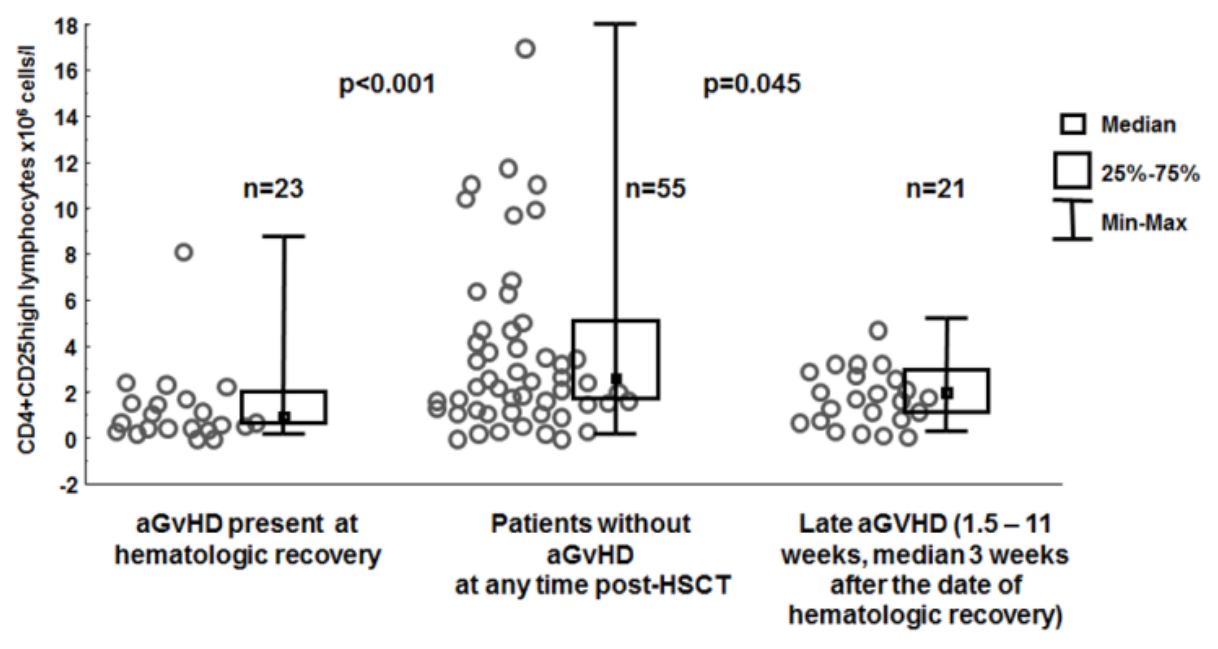

Figure 2. Numbers of $\mathrm{CD} 4+\mathrm{CD} 25$ high lymphocytes in the blood at hematologic recovery in patients with and without acute graft-versus-host disease (aGvHD) at the time of examination or at a later time point post-transplant.

Table 3. Multivariate analyses of the factors associated with aGvHD (grades I-IV).

\begin{tabular}{|c|c|c|c|c|}
\hline \multicolumn{5}{|c|}{ Entire group, $n=99$} \\
\hline Parameters & $\begin{array}{c}\text { Number of } \mathrm{CD} 4+ \\
\text { lymphocytes }\left(\times 10^{3} \text { cells } / \mathrm{L}\right)\end{array}$ & $\begin{array}{l}\text { Percentage of } \\
\text { CD4+CD25high } \\
\text { lymphocytes }\end{array}$ & $\begin{array}{l}\text { Number of CD4+CD25high } \\
\text { lymphocytes }\left(\times 10^{3} \text { cells } / \mathrm{L}\right)\end{array}$ & $\begin{array}{l}\text { MUD } \\
\text { donor }\end{array}$ \\
\hline Coefficient & 0.001 & 1.394 & -0.529 & 0.963 \\
\hline$p$ value & 0.496 & 0.223 & 0.031 & 0.047 \\
\hline Odds ratio & 1.001 & 4.031 & 0.589 & 2.619 \\
\hline$-95 \% \mathrm{Cl}$ & -0.003 & -0.863 & -1.009 & 0.014 \\
\hline$+95 \% \mathrm{Cl}$ & 0.005 & 3.651 & -0.049 & 1.911 \\
\hline \multicolumn{5}{|c|}{ In vivo T cell-depleted group (patients receiving ATG or Campath), $n=73$} \\
\hline Parameters & HLA mismatch & $\begin{array}{c}\text { Anti-CMV IgG } \\
\text { serostatus (D-/R+) }\end{array}$ & $\begin{array}{l}\text { Number of CD4+CD25high } \\
\text { lymphocytes }\left(\times 10^{3} \text { cells } / \mathrm{L}\right)\end{array}$ & $\begin{array}{l}\text { MUD } \\
\text { donor }\end{array}$ \\
\hline Coefficient & 0.600 & -0.423 & -0.363 & 1.970 \\
\hline$p$ value & 0.347 & 0.487 & 0.048 & 0.029 \\
\hline Odds ratio & 1.822 & 0.655 & 0.696 & 7.173 \\
\hline$-95 \% \mathrm{Cl}$ & 0.515 & 0.196 & 0.485 & 1.224 \\
\hline$+95 \% \mathrm{Cl}$ & 6.450 & 2.194 & 0.997 & 42.016 \\
\hline
\end{tabular}

* Table 3 shows the results of the forward stepwise logistic regression analysis. During the first step analysis, we included factors that had already been suggested [21,23,24,36,40-42] to contribute to the risk of aGvHD, including the type of donor (sibling or unrelated), the level of donor-recipient HLA matching (9/10 or less vs. 10/10 and sibling-matched transplantations), CMV reactivation events during the first year post-HSCT, age, anti-CMV-IgG serology (donor serology and donor/recipient serology: negative/positive), mode of transplantation (MAC vs. RIC), transplant material (peripheral blood progenitor cells (PBPCs) vs. bone marrow (BM)), the female-to-male transplantation, percentage and the numbers of $\mathrm{CD} 4+$ and $\mathrm{CD} 4+\mathrm{CD} 25$ high lymphocytes. 
The CD4+CD25high lymphocyte count at hematologic recovery was able to discriminate patients at risk for acute (low value) or de novo chronic (high value) GvHD $\left(3.778 \pm 0.780 \times 10^{6}\right.$ cells/1 vs. $2.042 \pm 0.261 \times 10^{6}$ cells $/ \mathrm{L}, p=0.041$, Figure 3).

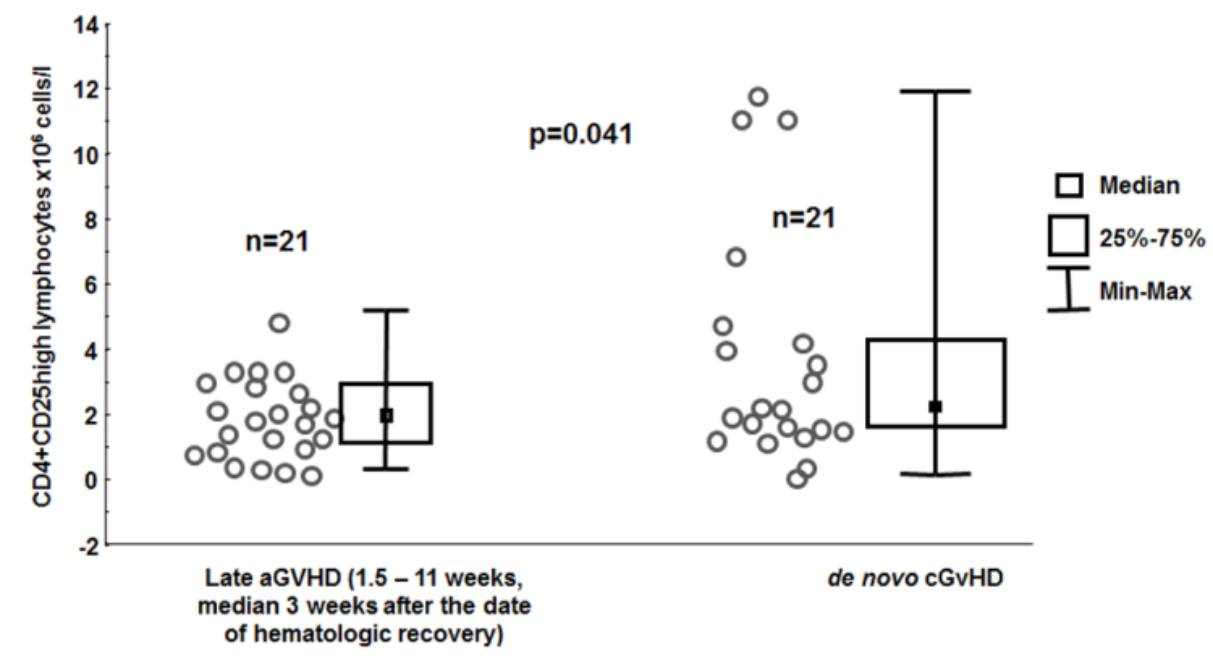

Figure 3. Numbers of CD4+CD25high lymphocytes in the blood determined at the beginning of hematologic recovery in the groups of patients with late aGvHD and those with de novo cGvHD.

CD4+CD25high lymphocyte levels at hematologic recovery were analyzed in a step-wise manner to determine the values that discriminated patients according to their survival post-HSCT. It appeared that lower proportions $(\leq 0.4 \%)$ and numbers $\left(\leq 2.5 \times 10^{6}\right.$ cells/L) of CD4+CD25high lymphocytes were associated with worse patient survival ( $56 \% v s .38 \%$, four-year survival, $p=0.040$ Figure 4 ).
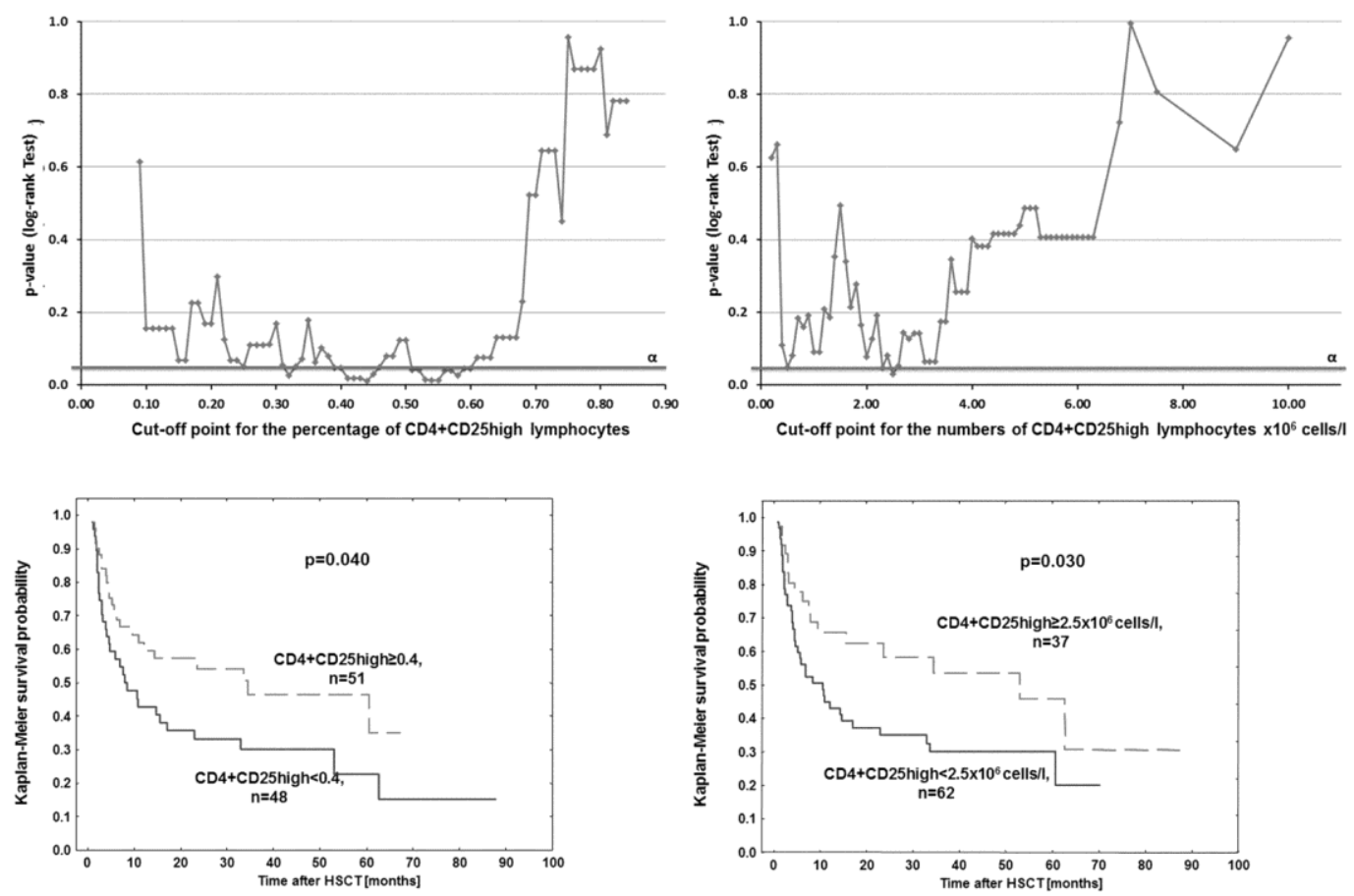

Figure 4. Overall survival of patients with higher and lower proportions and numbers $(<0.4 \%$ and $<2.5 \times 106$ cells/L, or the discriminative values for proportions and numbers, 
respectively) of CD4+CD25high lymphocytes (lower panel) based on the cut-off point analysis (upper panel). The optimal cut-off point selected was the point with the maximum log-rank statistic close to a $50 / 50$ split of patients.

\section{Discussion}

CMV infection exerts a profound effect upon the immune system [28]. Several studies performed on mice [43] as well as on people [25] showed that in consequence of CMV infection there is a shift in blood lymphocyte composition in favor of more mature cells. At the beginning of the repetitive CMV reactivation, in young individuals, the potential to combat infection may increase $[44,45]$, but with time the population of mature T cells increases including, CD57+ lymphocytes and those exhausted being PD-1 positive. The latter cells promote Treg cells expansion and functioning. More recently Terrazzini et al. [46] documented the fact that CMV-specific iTregs recognizing the same antigens as conventional CD4+ T cells are significantly more frequent in anti-CMV-IgG positive healthy individuals as compared to seronegative ones. They suppressed antigen-specific and nonspecific proliferation and in a large part expressed Foxp3. HSCT is a procedure in which transplanted cells repopulate the patient's immune system and the transplanted lymphocytes off-spring seen at hematologic recovery in the blood reflect the profile of transplanted lymphocytes in other words reflect the immune system characteristics of the donor. With this knowledge we started research on the profiling of blood lymphocytes at hematologic recovery focusing on CD4+ lymphocytes and its CD25high subpopulation to find out whether anti-CMV-IgG seropositivity of donors influences the repopulation potential of transplanted lymphocytes. The results of this study are in line with previous reports of the lower susceptibility to acute GvHD of patients with higher counts of CD4+CD25high lymphocytes in the blood [47-49], but it represents the first documentation of an association between higher levels of CD4+CD25high lymphocytes in the blood and anti-CMV-IgG positivity in transplant donors. The rationale behind these findings can be drawn from several research reports, as quoted below.

CD4+CD25high lymphocytes are either FoxP3 positive (over 80\% [50,51]) or promptly express this transcription factor $(2-4 \mathrm{~h})$ following IL-2 exposure [52,53] in soluble form or bound to dendritic cells and the extracellular matrix [54]. IL-2 is crucial for the maintenance of regulatory Tregs and for the differentiation of CD4+ T cells into defined effector $\mathrm{T}$ cell subsets following antigen-mediated activation, thus favoring either an immune response or suppression. Therefore, counting CD4+CD25high lymphocytes may provide information on the total number of cells equipped with FoxP3 and those ready to express this factor under short IL-2 stimulation.

Anti-CMV-IgG positivity is closely correlated with the presence of a cellular response in the same individual and reflects primary CMV infection and the presence of the virus in a latent form $[55,56]$. Reactivation events boost the immune response, promoting the effectiveness of specific surveillance [57].

Reactivation events are usually frequent in anti-CMV-positive healthy donors and result in (I) a skewing of the lymphocyte profile into one that is characteristic of more mature cells, including CD57 positive, CD28 negative and CD26 negative [58,59] lymphocytes that are less prone to active proliferation and (II) the appearance of blood Tregs that are primarily CMV specific and are then able to suppress antigen-specific and nonspecific proliferation [46]. The immediate outcome of HSCT, particularly aGvHD, depends largely on the composition and functional properties of $\mathrm{T}$ cells present in the 
inoculum [60-63]. We found a correlation between the level of toxicity and proportion of CD4+ cells what may have an association with known presence of CD4+ lymphocyte at the site of skin toxic lesions (own observation, unpublished). In aGvHD CD4+ cells play a role at the level of alloantigen presentation but do not usually colonize the epithelium in which process CD8+ predominate [64].

In solid organ transplantation Treg cells mitigate chronic rejection but -not acute episodes [65,66]. It might be due to the complex relationship between CMV reactivation risk and Treg cells [67]. Pro-inflammatory cytokines likely generated early post-transplant increase the risk of CMV reactivation and this virus if activated has immunosuppressive potential e.g., encoding Il-10. Therefore CMV infection plays a role in both hematopoietic and solid organ transplantation shaping their outcome [68,69]. The complex relationship between the level of Tregs and alloreactive complications is also seen in patients post HSCT. It was shown that cGvHD but not aGvHD is characterized by high CD4+CD25 high lymphocytes values in blood [70-72]. Interestingly, higher values of CD4+CD25high lymphocytes were seen in the blood of patients at risk of de novo cGvHD (Figure 3) before the clinical symptomatology of this alloreactivity was clinically apparent This novel finding may assist the physician's decision in planning the follow-up of patients post HSCT. This data helps to explain the lower incidence of aGvHD in patients who receive transplants from anti-CMV-IgG-positive donors. They have higher proportions of CD4+CD25high lymphocytes during the first wave of lymphocyte recovery. Interestingly, CD4+ lymphocytes were also higher in patients who received HSCT from anti-CMV-IgG-positive donors. However, in the multivariate analysis, only the level of CD4+CD25high lymphocytes played an independent and significant role in protection against aGvHD; no such effect was observed for the level of CD4+ lymphocytes. In our estimation, the higher values of CD4+ lymphocytes in the blood and a lower demand for IgG support of patients transplanted from anti-CMV-IgG positive donors reflect the higher potential of the immune system of patients constantly alerted by CMV repetitive reactivations. As a result at the early stages of chronic CMV infection the potential to combat infection may even increase $[44,45]$.

In conclusion, the fate of HSCT patients depends significantly on the CMV status of the donors. If they are positive for anti-CMV-IgG antibodies, the immune system of recipients is doing better shortly after transplant, CD4+CD25high lymphocytes are in higher number what translates into the lower incidence of aGvHD. Higher levels of CD4+CD25high lymphocytes increase the chances of survival.

\section{Acknowledgments}

This study was financially supported by the National Centre for Research (grant N N402 430039) and The National Centre for Research and Development (grant number INNOMED/I/1 /NCBR/2014) from the Innovative Economy Operational Programme founds, in the framework of the European Regional Development Fund..

\section{Author Contributions}

E.J. participated in writing the article, participated in the statistical analysis and performed the viral work; D.D. performed the CD4+CD25high lymphocyte-related work and participated in the data analysis; A.T. performed the viral work; A.B. participated in the CD4+CD25high lymphocyte-related 
data analysis; J.L., M.D.M., M.S., and K.S. provided the medical data; S.M. performed data management and statistical analysis; and A.L. designed the study, wrote the paper and participated in the data analysis.

\section{Conflicts of Interest}

The authors declare no conflict of interest

\section{References}

1. Ovsyannikova, I.G.; Jacobson, R.M.; Ryan, J.E.; Dhiman, N.; Vierkant, R.A.; Poland, G.A. Relationship between HLA polymorphisms and gamma interferon and interleukin-10 cytokine production in healthy individuals after rubella vaccination. Clin. Vaccine Immunol. 2007, 14, 115-122.

2. Walldén, J.; Ilonen, J.; Roivainen, M.; Ludvigsson, J.; Vaarala, O. Effect of HLA genotype or CTLA-4 polymorphism on cytokine response in healthy children. Scand. J. Immunol. 2008, 68, 345-350.

3. Vasto, S.; Colonna-Romano, G.; Larbi, A.; Wikby, A.; Caruso, C.; Pawelec, G. Role of persistent CMV infection in configuring $\mathrm{T}$ cell immunity in the elderly. Immun. Ageing 2007, 4, 2. doi:10.1186/1742-4933-4-2.

4. Caruso, C.; Candore, G.; Modica, M.; Bonanno, C.; Sireci, G.; Dieli, F.; Salerno, A. HLA and cytkine production. J. Interferon Cytokine Res. 1996, 16, 983-988.

5. Fürst, D.; Müller, C.; Vucinic, V.; Bunjes, D.; Herr, W.; Gramatzki, M.; Schwerdtfeger, R.; Arnold, R.; Einsele, H.; Wulf, G.; et al. High-resolution HLA matching in hematopoietic stem cell transplantation: A retrospective collaborative analysis. Blood 2013, 122, 3220-3229.

6. Duquesnoy, R.J. HLA epitope based matching for transplantation. Transpl. Immunol. 2014, 31, 1-6.

7. Takahashi, T.; Sakaguchi, S. The role of regulatory T cells in controlling immunologic self-tolerance. Int. Rev. Cytol. 2003, 225, 1-32.

8. Takahashi, T.; Sakaguchi, S. Naturally arising CD25+CD4+ regulatory T cells in maintaining immunologic self-tolerance and preventing autoimmune disease. Curr. Mol. Med. 2003, 3, 693-706.

9. Nishimura, E.; Sakihama, T.; Setoguchi, R.; Tanaka, K.; Sakaguchi, S. Induction of antigen-specific immunologic tolerance by in vivo and in vitro antigen-specific expansion of naturally arising Foxp3+CD25+CD4+ regulatory T cells. Int. Immunol. 2004, 16, 1189-1201.

10. Sakaguchi, S.; Sakaguchi, N.; Asano, M.; Itoh, M.; Toda, M. Immunologic self-tolerance maintained by activated T cells expressing IL-2 receptor alpha-chains (CD25). Breakdown of a single mechanism of self-tolerance causes various autoimmune diseases. J. Immunol. 1995, 155, 1151-1164.

11. Zhang, Y.; Maksimovic, J.; Naselli, G.; Qian, J.; Chopin, M.; Blewitt, M.E.; Oshlack, A.; Harrison, L.C. Genome-wide DNA methylation analysis identifies hypomethylated genes regulated by FOXP3 in human regulatory T cells. Blood 2013, 122, 2823-2836.

12. Horwitz, D.A.; Zheng, S.G.; Gray, J.D. The role of the combination of IL-2 and TGF-beta or IL-10 in the generation and function of CD4+ CD25+ and CD8+ regulatory T cell subsets. J. Leukoc. Biol. 2003, 74, 471-478.

13. Zheng, S.G.; Wang, J.H.; Gray, J.D.; Soucier, H.; Horwitz, D.A. Natural and induced CD4+CD25+ cells educate CD4+CD25- cells to develop suppressive activity: The role of IL-2, TGF-beta, and IL-10.

J. Immunol. 2004, 172, 5213-5221. 
14. Liu, W.; Putnam, A.L.; Xu-Yu, Z.; Szot, G.L.; Lee, M.R.; Zhu, S.; Gottlieb, P.A.; Kapranov, P.; Gingeras, T.R.; Fazekas de St Groth, B.; et al. CD127 expression inversely correlates with FoxP3 and suppressive function of human CD4+ T reg cells. J. Exp. Med. 2006, 203, 1701-1711.

15. Seddiki, N.; Santner-Nanan, B.; Martinson, J.; Zaunders, J.; Sasson, S.; Landay, A.; Solomon, M.; Selby, W.; Alexander, S.I.; Nanan, R.; et al. Expression of interleukin (IL)-2 and IL-7 receptors discriminates between human regulatory and activated T cells. J. Exp. Med. 2006, 203, 1693-700.

16. Sojka, D.K.; Huang, Y.H.; Fowell, D.J. Mechanisms of regulatory T-cell suppression-A diverse arsenal for a moving target. Immunology 2008, 124, 13-22.

17. Sakaguchi, S.; Wing, K.; Onishi, Y.; Prieto-Martin, P.; Yamaguchi, T. Regulatory T cells: How do they suppress immune responses? Int. Immunol. 2009, 21, 1105-1111.

18. Engelhardt, B.G.; Crowe, J.E. Homing in on acute graft $v s$. host disease: Tissue-specific T regulatory and Th17 cells. Curr. Top. Microbiol. Immunol. 2010, 341, 121-146.

19. Thornton, A.M.; Donovan, E.E.; Piccirillo, C.A.; Shevach, E.M. Cutting Edge: IL-2 Is Critically Required for the In Vitro Activation of CD4+CD25+ T Cell Suppressor Function. J. Immunol. 2004, 172, 6519-6523.

20. Jacobsen, N.; Lönnqvist, B.; Ringdén, O.; Rajantie, J.; Siimes, M.A.; Volin, L.; Ruutu, T.; Nikoskelainen, J.; Toivanen, A.; Ryder, L. Graft-versus-leukaemia activity associated with cytomegalovirus seropositive bone marrow donors but separated from graft-versus-host disease in allograft recipients with AML. Eur. J. Haematol. 1987, 38, 350-255.

21. Remberger, M.; Mattsson, J.; Hassan, Z.; Karlsson, N.; LeBlanc, K.; Omazic, B.; Okas, M.; Sairafi, D.; Ringdén, O. Risk factors for acute graft-versus-host disease grades II-IV after reduced intensity conditioning allogeneic stem cell transplantation with unrelated donors: A single centre study. Bone Marrow Transplant. 2008, 41, 399-405.

22. Jaskula, E.; Bochenska, J.; Kocwin, E.; Tarnowska, A.; Lange, A. CMV Serostatus of Donor-Recipient Pairs Influences the Risk of CMV Infection/Reactivation in HSCT Patients. Bone Marrow Res. 2012, 2012, 375075.

23. Jaskula, E.; Dlubek, D.; Sedzimirska, M.; Duda, D.; Tarnowska, A. Lange, a Reactivations of cytomegalovirus, human herpes virus 6, and Epstein-Barr virus differ with respect to risk factors and clinical outcome after hematopoietic stem cell transplantation. Transplant. Proc. 2010, 42, 3273-3276.

24. Jaskula, E.; Lange, A.; Dlubek, D.; Kyrcz-Krzemień, S.; Markiewicz, M.; Dzierzak-Mietla, M.; Jedrzejczak, W.W.; Gronkowska, A.; Nowak, J.; Warzocha, K.; et al. IL-10 promoter polymorphisms influence susceptibility to aGvHD and are associated with proportions of CD4+FoxP3+ lymphocytes in blood after hematopoietic stem cell transplantation. Tissue Antigens 2013, 82, 387-396.

25. Herndler-Brandstetter, D.; Landgraf, K.; Tzankov, A.; Jenewein, B.; Brunauer, R.; Laschober, G.T.; Parson, W.; Kloss, F.; Gassner, R.; Lepperdinger, G.; Grubeck-Loebenstein, B. The impact of aging on memory $\mathrm{T}$ cell phenotype and function in the human bone marrow. J. Leukoc. Biol. 2012, 91 , 197-205.

26. McIver, Z.; Melenhorst, J.J.; Wu, C.; Grim, A.; Ito, S.; Cho, I.; Hensel, N.; Battiwalla, M.; Barrett, A.J. Donor lymphocyte count and thymic activity predict lymphocyte recovery and outcomes after matched-sibling hematopoietic stem cell transplant. Haematologica 2013, 98, 346-352. 
27. Azuma, E.; Hirayama, M.; Yamamoto, H.; Komada, Y. The role of donor age in naive T-cell recovery following allogeneic hematopoietic stem cell transplantation: The younger the better. Leuk. Lymphoma 2002, 43, 735-739.

28. Hanley, P.J.; Bollard, C.M. Controlling cytomegalovirus: Helping the immune system take the lead. Viruses 2014, 6, 2242-2258.

29. Snydman, D.R. Editorial commentary: The complexity of latent cytomegalovirus infection in stem cell donors. Clin. Infect. Dis. 2014, 59, 482-483.

30. Boeckh, M.; Nichols, W.G. The impact of cytomegalovirus serostatus of donor and recipient before hematopoietic stem cell transplantation in the era of antiviral prophylaxis and preemptive therapy. Blood 2004, 103, 2003-2008.

31. Ljungman, P.; Brand, R.; Hoek, J.; de la Camara, R.; Cordonnier, C.; Einsele, H.; Styczynski, J.; Ward, K.N.; Cesaro, S. Donor cytomegalovirus status influences the outcome of allogeneic stem cell transplant: A study by the European group for blood and marrow transplantation. Clin. Infect. Dis. 2014, 59, 473-481.

32. Ljungman, P. The role of cytomegalovirus serostatus on outcome of hematopoietic stem cell transplantation. Curr. Opin. Hematol. 2014, 21, 466-469.

33. Ljungman, P.; Brand, R.; Einsele, H.; Frassoni, F.; Niederwieser, D.; Cordonnier, C. Donor CMV serologic status and outcome of CMV-seropositive recipients after unrelated donor stem cell transplantation: An EBMT megafile analysis. Blood 2003, 102, 4255-4260.

34. Jaskula, E.; Dlubek, D.; Duda, D.; Bogunia-Kubik, K.; Mlynarczewska, A.; Lange, A. Interferon gamma 13-CA-repeat homozygous genotype and a low proportion of $\mathrm{CD}^{+}$lymphocytes are independent risk factors for cytomegalovirus reactivation with a high number of copies in hematopoietic stem cell transplantation recipients. Biol. Blood Marrow Transplant. 2009, 15, 1296-305.

35. CMV IgG Test System. Available online: http://www.zeusscientific.com/products/technologysystems/elisa/ (accessed on 19 March 2015).

36. Jaskula, E.; Lange, A.; Kyrcz-Krzemien, S.; Markiewicz, M.; Dzierzak-Mietla, M.; Jedrzejczak, W.W.; Czajka, P.; Mordak-Domagala, M.; Lange, J.; Gronkowska, A.; et al. NOD2/CARD15 single nucleotide polymorphism 13 (3020insC) is associated with risk of sepsis and single nucleotide polymorphism $8(2104 \mathrm{C}>\mathrm{T})$ with herpes viruses reactivation in patients after allogeneic hematopoietic stem cell transplantation. Biol. Blood Marrow Transplant. 2014, 20, 409-414.

37. Ljungman, P.; Hakki, M.; Boeckh, M. Cytomegalovirus in hematopoietic stem cell transplant recipients. Infect. Dis. Clin. N. Am. 2010, 24, 319-337.

38. Ljungman, P.; Hakki, M.; Boeckh, M. Cytomegalovirus in hematopoietic stem cell transplant recipients. Hematol. Oncol. Clin. N. Am. 2011, 25, 151-169.

39. George, B.; Pati, N.; Gilroy, N.; Ratnamohan, M.; Huang, G.; Kerridge, I.; Hertzberg, M.; Gottlieb, D.; Bradstock, K. Pre-transplant cytomegalovirus (CMV) serostatus remains the most important determinant of CMV reactivation after allogeneic hematopoietic stem cell transplantation in the era of surveillance and preemptive therapy. Transpl. Infect. Dis. 2010, 12, 322-329.

40. Ringdén, O.; Labopin, M.; Solders, M.; Beelen, D.; Arnold, R.; Ehninger, G.; Milpied, N.; Niederwieser, D.; Hamladji, R.M.; Kyrcz-Krzemien, S.; et al. Who Is the Best Hematopoietic Stem-Cell Donor for a Male Patient With Acute Leukemia? Transplantation 2014, 98, 569-577 
41. Gratwohl, A.; Brand, R.; Apperley, J.; Biezen, A.V; Bandini, G.; Devergie, A.; Schattenberg, A.; Frassoni, F.; Guglielmi, C.; Iacobelli, S.; et al. Graft-versus-host disease and outcome in HLA-identical sibling transplantations for chronic myeloid leukemia. Blood 2002, 100, 3877-3886.

42. Jagasia, M.; Arora, M.; Flowers, M.E.D.; Chao, N.J.; McCarthy, P.L.; Cutler, C.S.; Urbano-Ispizua, A.; Pavletic, S.Z.; Haagenson, M.D.; Zhang, M.J.; et al. Risk factors for acute GVHD and survival after hematopoietic cell transplantation. Blood 2012, 119, 296-307.

43. Cicin-Sain, L.; Brien, J.D.; Uhrlaub, J.L.; Drabig, A.; Marandu, T.F.; Nikolich-Zugich, J. Cytomegalovirus infection impairs immune responses and accentuates T-cell pool changes observed in mice with aging. PLoS Pathog. 2012, 8, e1002849.

44. Strioga, M.; Pasukoniene, V.; Characiejus, D. CD8+CD28- and CD8+ CD57+ T cells and their role in health and disease. Immunology 2011, 134, 17-32.

45. Lee, S.A.; Sinclair, E.; Hatano, H.; Hsue, P.Y.; Epling, L.; Hecht, F.M.; Bangsberg, D.R.; Martin, J.N.; McCune, J.M.; Deeks, S.G.; et al. Impact of HIV on CD8+ T cell CD57 expression is distinct from that of CMV and aging. PLoS One 2014, 9, e89444.

46. Terrazzini, N.; Bajwa, M.; Vita, S.; Cheek, E.; Thomas, D.; Seddiki, N.; Smith, H.; Kern, F. A novel cytomegalovirus-induced regulatory-type $\mathrm{T}$-cell subset increases in size during older life and links virus-specific immunity to vascular pathology. J. Infect. Dis. 2014, 209, 1382-1392.

47. Magenau, J.M.; Qin, X.; Tawara, I.; Rogers, C.E.; Kitko, C.; Schlough, M.; Bickley, D.; Braun, T.M.; Jang, P.S.; Lowler, K.P.; et al. Frequency of $\mathrm{CD} 4{ }^{+} \mathrm{CD} 25^{\text {hi }} \mathrm{FOXP} 3^{+}$regulatory $\mathrm{T}$ cells has diagnostic and prognostic value as a biomarker for acute graft-versus-host-disease. Biol. Blood Marrow Transplant. 2010, 16, 907-914.

48. Schneider, M.; Munder, M.; Karakhanova, S.; Ho, A.D.; Goerner, M. The initial phase of graft-versus-host disease is associated with a decrease of CD4+CD25+ regulatory $\mathrm{T}$ cells in the peripheral blood of patients after allogeneic stem cell transplantation. Clin. Lab. Haematol. 2006, 28, 382-390.

49. Zhai, Z.; Sun, Z.; Li, Q.; Zhang, A.; Liu, H.; Xu, J.; Xu, X.; Geng, L.; Harris, D.; Hu, S.; Wang, Y. Correlation of the $\mathrm{CD} 4+\mathrm{CD} 25$ high $\mathrm{T}$-regulatory cells in recipients and their corresponding donors to acute GVHD. Transpl. Int. 2007, 20, 440-446.

50. Baecher-Allan, C.; Brown, J.A.; Freeman, G.J.; Hafler, D.A. CD4+CD25high Regulatory Cells in Human Peripheral Blood. J. Immunol. 2001, 167, 1245-1253.

51. Roncador, G.; Brown, P.J.; Maestre, L.; Hue, S.; Martínez-Torrecuadrada, J.L.; Ling, K.L.; Pratap, S.; Toms, C.; Fox, B.C.; Cerundolo, V.; et al. Analysis of FOXP3 protein expression in human CD4+CD25+ regulatory T cells at the single-cell level. Eur. J. Immunol. 2005, 35, 1681-1691.

52. Zheng, S.G.; Wang, J.; Wang, P.; Gray, J.D.; Horwitz, D.A. IL-2 is essential for TGF-beta to convert naive CD4+CD25- cells to CD25+Foxp3+ regulatory T cells and for expansion of these cells. J. Immunol. 2007, 178, 2018-2027.

53. Zorn, E.; Nelson, E.A.; Mohseni, M.; Porcheray, F.; Kim, H.; Litsa, D.; Bellucci, R.; Raderschall, E.; Canning, C.; Soiffer, R.J.; et al. IL-2 regulates FOXP3 expression in human CD4+CD25+ regulatory $\mathrm{T}$ cells through a STAT-dependent mechanism and induces the expansion of these cells in vivo. Blood 2006, 108, 1571-1579.

54. Boyman, O.; Sprent, J. The role of interleukin-2 during homeostasis and activation of the immune system. Nat. Rev. Immunol. 2012, 12, 180-190. 
55. Sester, M.; Gärtner, B.C.; Sester, U.; Girndt, M.; Mueller-Lantzsch, N.; Köhler, H. Is the cytomegalovirus serologic status always accurate? A comparative analysis of humoral and cellular immunity. Transplantation 2003, 76, 1229-1230.

56. Alcami, A.; Koszinowski, U.H. Viral mechanisms of immune evasion. Trends Microbiol. 2000, 21, 3542-3547.

57. Jones, R.P. Infectious-like Spread of an Agent Leading to Increased Medical Admissions and Deaths in Wigan ( England ), during 2011 and 2012. Br. J. Med. Med. Res. 2014, 4, 4723-4741.

58. Alonso Arias, R.; Moro-García, M.A.; Echeverría, A.; Solano-Jaurrieta, J.J.; Suárez-García, F.M.; López-Larrea, C. Intensity of the humoral response to cytomegalovirus is associated with the phenotypic and functional status of the immune system. J. Virol. 2013, 87, 4486-4495.

59. Bour-Jordan, H.; Blueston, J. CD28 function: A balance of costimulatory and regulatory signals. J. Clin. Immunol 2002, 22, 1-7.

60. Zhang, Y.; Joe, G.; Hexner, E.; Zhu, J.; Emerson, S.G. Alloreactive Memory T Cells Are Responsible for the Persistence of Graft-versus-Host Disease. J. Immunol. 2005, 174, 3051-3058.

61. Paz Morante, M.; Briones, J.; Canto, E.; Sabzevari, H.; Martino, R.; Sierra, J.; Rodriguez-Sanchez, J.L.; Vidal, S. Activation-associated phenotype of CD3 T cells in acute graft-versus-host disease. Clin. Exp. Immunol. 2006, 145, 36-43.

62. Choi, S.W.; Levine, J.E.; Ferrara, J.L. M. Pathogenesis and management of graft-versus-host disease. Immunol. Allergy Clin. N. Am. 2010, 30, 75-101.

63. Ferrara, J.L.M.; Levine, J.E.; Reddy, P.; Holler, E. Graft-versus-host disease. Lancet 2009, 373, 1550-1561.

64. Ball, L.M.; Egeler, R.M. Acute GvHD: Pathogenesis and classification. Bone Marrow Transplant. 2008, 41, S58-S64.

65. Issa, F.; Wood, K.J. CD4+ regulatory T cells in solid organ transplantation. Curr. Opin. Organ Transplant. 2010, 15, 757-764.

66. San Segundo, D.; Millán, O.; Muñoz-Cacho, P.; Boix, F.; Paz-Artal, E.; Talayero, P.; Morales, J.M.; Muro, M.; de Cos, M.Á.; Guirado, L.; et al. High Proportion of Pretransplantation Activated Regulatory T cells (CD4+CD25highCD62L+CD45RO+) Predicts Acute Rejection in Kidney Transplantation. Transplantation 2014, 98, 1213-1218.

67. Lindenberg, M.; Solmaz, G.; Puttur, F.; Sparwasser, T. Mouse Cytomegalovirus infection overrules T regulatory cell suppression on natural killer cells. Virol J. 2014, 9, 145-157.

68. Potena, L.; Valantine, H. a Cytomegalovirus-associated allograft rejection in heart transplant patients. Curr. Opin. Infect. Dis. 2007, 20, 425-431.

69. Perez-Sola, M.J.; Caston, J.J.; Solana, R.; Rivero, A.; Torre-Cisneros, J. Indirect effects of cytomegalovirus infection in solid organ transplant recipients. Enferm. Infecc. Microbiol. Clin. 2008, 26, 38-47.

70. Zorn, E.; Kim, H.T.; Lee, S.J.; Floyd, B.H.; Litsa, D.; Arumugarajah, S.; Bellucci, R.; Alyea, E.P.; Antin, J.H.; Soiffer, R.J.; et al. Reduced frequency of FOXP3 + CD4 + CD25 + regulatory T cells in patients with chronic graft-versus-host disease. 2005, 106, 2903-2911.

71. Anderson, B.E.; Mcniff, J.M.; Matte, C.; Athanasiadis, I.; Shlomchik, W.D.; Shlomchik, M.J. Recipient CD4 + T cells that survive irradiation regulate chronic graft-versus-host disease. 2004, $104,1565-1573$. 
72. Rieger, K.; Loddenkemper, C.; Maul, J.; Fietz, T.; Wolff, D.; Terpe, H.; Steiner, B.; Berg, E.; Miehlke, S.; Bornha, M.; et al. Mucosal FOXP3 + regulatory T cells are numerically deficient in acute and chronic GvHD. 2006, 107, 1717-1723.

(C) 2015 by the authors; licensee MDPI, Basel, Switzerland. This article is an open access article distributed under the terms and conditions of the Creative Commons Attribution license (http://creativecommons.org/licenses/by/4.0/). 